\title{
An Analysis of Total Quality Management (TQM) within the Thai Auto Parts Sector
}

\author{
https://doi.org/10.3991/ijoe.v16i02.11917 \\ Att Petcharit $^{(\bowtie)}$, Puris Sornsaruht, Paitoon Pimdee \\ King Mongkut's Institute of Technology Ladkrabang (KMITL), Bangkok, Thailand \\ $56611239 @ \mathrm{kmitl} . \mathrm{ac} . \mathrm{th}$
}

\begin{abstract}
The study intended to investigate the factors that affect the total quality management (TQM) process in the 1,800 firm Thai auto parts industry. Automotive parts export shipments from Thailand are ranked 13th globally and are destined for over 100 countries, with Thailand's combined automotive industry representing $12 \%$ of GDP. Therefore, with the authors understanding the importance of this economic sector, a research tool was developed, which contained a five-level scale to investigate 455 auto parts managers, executives, and owners' opinions. Topics surveyed included the respondents' opinions on the effects of knowledge management (KNG), product quality (QLY), strategic planning (STY), and technology and innovation (TIN) on the Thai auto part industry TQM process. The study's eight hypotheses made use LISREL 9.1 software to analyze the final structural equation model (SEM). Results showed that all the model's variables had a positive influence on TQM, which can be combined to explain the variance of the factors affecting TQM $\left(\mathrm{R}^{2}\right)$ by $78 \%$. Additionally, the variables affecting TQM ranked in importance were STY, KNG, QLY, and TIN. Disruptive change has also arrived within the automotive sector, as Industry 4.0 technologies, the Internet of Things (IoT), and artificial intelligence (AI) are being used in the development of a new generation of autonomous and electric vehicles (EVs), making many current manufacturers' technologies and processes obsolete. Therefore, management and vendors must embrace these changes for their survival. The study's results highlight the necessity for international firms to embrace innovation and technological change to retain a competitive advantage or even their survival. Governments and educational institutions must also go the 'extra mile' to support their domestic automotive and auto parts sectors.
\end{abstract}

Keywords—Knowledge management, product quality, strategic planning, technology and innovation, TQM

\section{Introduction}

Thailand is the $13^{\text {th }}$ biggest vehicle parts exporter in the world, whose exports now reach over 100 countries worldwide. Furthermore, 60 of the 100 biggest global auto part suppliers are currently producing in Thailand, with $90 \%$ of the parts manufactured used in auto vehicle production domestically. 
Furthermore, in 2017, Thailand held 12th place in global vehicle production with 1.989 million units, although this was significantly lower than the peak years of 2012 and 2013, in which 2.454 and 2.457 million units were produced, respectively [1]. However, today, Thailand is the largest vehicle producer within Southeast Asia [2], with 21 vehicle assembly plants and 11 motorcycle plants. Furthermore, there are 720 tier-one and 1,100 tier-two and tier-three auto parts manufacturers [3]. Thailand also possesses the most significant automotive cluster in Southeast Asia, employing 850,000 people and contributing $12 \%$ to the country's GDP [2], [4], [5]. The Federation of Thai Industries (FTI) also estimates exports of automotive products were at $\$ 30.192$ billion in 2018, up from \$29.906 billion in 2017.

However, other emerging economies such as Vietnam and Indonesia are developing an automotive industry, while also learning from Thailand's mistakes and experiences. Therefore, Thailand needs to examine its automotive core competencies and adapt to industry upgrades that are necessary to meet global demands [4].

Furthermore, disruptive change has arrived within the automotive sector with technologies such as autonomous vehicles, EVs, the Internet of Things (IoT), and artificial intelligence (AI) [6], making many current manufacturers' technologies and processes obsolete [7], with management and vendors needing to embrace these changes for their very survival.

Therefore, this study undertakes an examination of the Thai auto parts industry, where a highly competitive global business environment and new and accelerating technology cycles are already creating a paradigm shift within the automotive sector [7 - 9]. Processes need to be implemented in firms of all sizes to increase product quality, therefore, reducing defects and waste, which leads to an increased competitive edge.

Also, regardless of the sector, its size, structure, or maturity, organizations need to establish an appropriate management framework to be successful [10]. One example is the EFQM (European Foundation for Quality Management) Excellence Model, which has become a practical organizational tool by measuring the path to excellence, while also helping firms understand the gaps and then stimulating solutions.

Another method evolving out of the 1950s for the process of TQM was the teaching of statistical analysis and quality control by Edwards Deming to Japanese executives and engineers [11]. Also, in 1954, Joseph M. Juran was invited to Japan, after which he made presentations to the top and middle-level managers. From these early contacts, the idea of total quality control was established as a management tool [12]. However, most probably, the scholar Armand V. Feigenbaum is the name most would associate with total quality control from his 1951 book [13], and subsequently, today's concept of TQM [14].

In Thailand, a vast number of auto parts firms are either owned or substantially influenced by Japanese companies. Therefore, one often hears the term Kaizen in regards to discussions concerning product quality. Masaaki Imai in the 1980s created the word Kaizen, which today many have identified as the Japanese equivalent to TQM [15]. However, Kaizen is different from TQM, as TQM uses multiple tools and techniques, while Kaizen serves as a new philosophical paradigm for the unification of knowledge and action [16]. 
Therefore, after the authors identified the present and future importance of the auto parts industry to the Thai economy, it was concluded that TQM was arguably the single most crucial factor in the sector's competitiveness and survival. As such, the authors developed the following research questions (RQs):

RQ1: What elements affect TQM success within the Thai auto parts industry?

RQ2: What are the possible implications of the success or failure of Thai auto parts firms to embrace the disruptive changes ahead?

RQ3: What are the levels of importance of the underlying factors related to TQM acceptance and implementation?

\section{Brief Literature Review}

The following section briefly discusses the study's five latent variables.

\subsection{Strategic planning (STY)}

From a study conducted at Toyota, it was stated that establishing a TQM process that assesses and diagnoses a firm's processes is one of the most significant challenges in a company's quality management strategy today [17]. This is consistent with a study stating that TQM plays a crucial role in strategy implementation importance [18], which is similar to a South African study, which also noted that STY plays a significant role in successfully implementing TQM [19].

\subsection{Technology and innovation (TIN)}

Furthermore, a recent OECD report discusses disruptive scientific, technological, and societal developments and the need for adaptive policies. However, these disruptions create new challenges both in organizations and governments, which, therefore, requires agility to ensure the public's trust and policy coherence [9].

Echoes of these ideas are also reflected in a McKinsey Global Institute (MGI) [20] report in which the diffusion of new digital technologies is addressed, which is stated to affect productivity performance while also causing disruption. However, if organizations and governments can embrace these changes, MGI estimates that global GDP could rise by an additional $\$ 13$ trillion due to digitization, automation, and AI, as these technologies create significant new business opportunities and productivity gains are reinvested in economies.

\subsection{Knowledge management (KNG)}

In a visionary automotive supply industry study, the authors sought out how to identify top performers from the followers [21]. From it, it was felt that most organizations believed that market position and productivity were essential elements. The study also stated that top performers are flexible and manage innovative and prosper- 
ous knowledge flows. The authors also stated that KNG and innovation were highly connected and vital variables within the industry leaders.

These concepts are also consistent with a Taiwanese study that investigated 1139 high-tech companies and stated that organizations face competitive challenges due to the quickening pace of technological change [22]. However, the study determined that KNG is correlated positively with innovation performance and TQM. In Malaysia, [23] also determined that KNG is crucial to small and medium-sized enterprises (SMEs) survivability, as well as being a crucial aspect in improving their innovation strategies. In Taiwan, KNG effectiveness is enhanced when firms co-locate, interact, and share resources within industrial clusters [24].

\subsection{Product quality (QLY)}

Another study defined QLY as a measure of development and defective rates [25], while another suggested there were eight perceived QLY dimensions, which included perception of quality, reliability, durability, serviceability, aesthetics, features, and conformance [26]. Also, the author suggested that a strategic approach is needed when companies implement quality management. Furthermore, Japanese manufacturers are known to focus on perceived quality, with the intent of using it as a competitive edge foothold in the automotive industry. It has also been suggested that global competition in the automotive industry forces companies to improve efficiency and quality [27].

\subsection{Total quality management (TQM)}

Finally, TQM can also be of great importance in how organizations manage their business, which also represents a fundamental change. TQM can also be complicated and time-consuming, as TQM's objectives are waste elimination, quality improvement, shorter lead times, costs reduction, improvement of employee morale, and continuous improvement [28]. However, once implemented, TQM profitability and competitiveness are likely outcomes [29], as well as service quality improvements and client gratification [30]. Finally, TQM stresses the need for customer orientation and requires discovery and an anticipation of the customer's needs and wants [31].

\subsection{Conceptualized framework}

From the authors' detailed literature analysis, the following eight hypotheses were developed, which are also presented in Figure 1.

H1: Strategic Planning (STY) directly and positively affects Knowledge Management (KNG).

H2: Strategic Planning (STY) directly and positively affects Product Quality (QLY).

H3: Strategic Planning (STY) directly and positively affects Total Quality Management (TQM). 
H4: Technology and Innovation (TIN) directly and positively affects Knowledge management (KNG).

H5: Technology and Innovation (TIN) directly and positively affects Product Quality (QLY).

H6: Knowledge Management (KNG) directly and positively affects Product Quality (QLY).

H7: Knowledge Management (KNG) directly and positively affects Total Quality Management (TQM).

H8: Product Quality (QLY) directly and positively affects Total Quality Management (TQM).

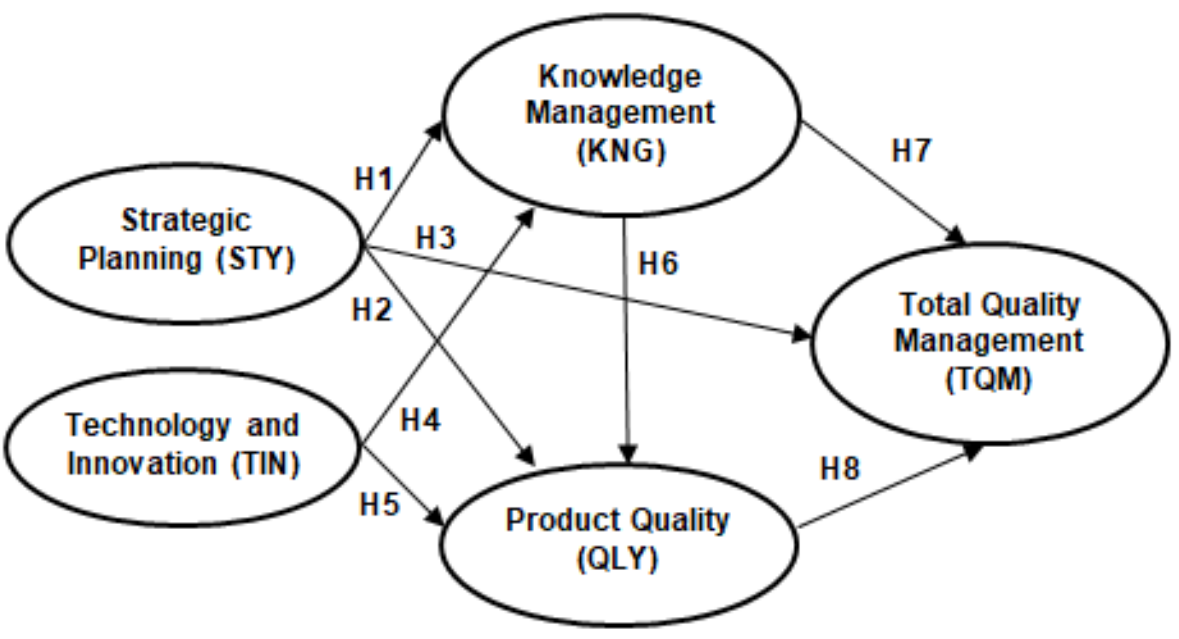

Fig. 1. TQM's conceptual model

\section{Methods}

\subsection{The study's questionnaire}

Section one of the questionnaire consisted of five items related to the respondent's gender, age, education level, work experience, and the company's total number of staff. Part two to six had items consisting of a five-level opinion scale, with ' 5 ' indicating 'strongly agree,' ' 3 ' indicating 'moderate agreement,' and ' 1 ' indicating 'strongly disagree.' Additionally, part two contained three items about strategic planning (STY), part three contained five items concerning technology and innovation (TIN), part four contained five items related to total quality management (TQM), part five was concerned with product quality (QLY), and finally, part six had three items about knowledge management (KNG). Five experts assisted with the questionnaire reliability testing, which was accessed by using Cronbach's $\alpha$. Results showed that item reliability ranged from $0.73-0.86$, with an $\alpha 0.7 \leq \alpha<0.8$ as 'acceptable'[32]. 


\subsection{Sample and data collection}

Sample sizes are a source of great academic debate. However, in confirmatory factor analysis (CFA) models, it has been suggested that a sample should include at least 200 participants [33], while other scholars have suggested 400, as bigger samples assure better CFA results [34].

Therefore, starting in May 2017, the researchers began a process of soliciting managers and executives of Thai auto parts enterprises to participate in the study's survey. The initial contact was a name and contact information randomly generated from a list of companies provided by various auto parts organizations and the Thai Ministry of Commerce. This process was quite exhaustive and lasted until October of 2017. The questionnaires collected met and exceeded the initial target of 400 , whose final audited number was 455 .

\subsection{Analysis of the data}

The variable analysis used for the CFA and the final SEM was conducted with the use of LISREL 9.1 software. Table 3 details the results of the goodness-of-fit (GoF) analysis.

\section{$4 \quad$ Results}

\subsection{Managers and executives survey characteristics}

The final audited questionnaire sample detailed the results from the 455 individuals. Results indicated that $59.12 \%$ were men, with the sample group each having $30.77 \%$ in the age groups $31-40$ and $41-50$. Additionally, $87.03 \%$ identified themselves as either a manager or executive, while the remaining $12.97 \%$ indicated that they were the firm's owner. Education levels for the group showed that only $2.86 \%$ had graduate degrees, with most having an undergraduate $(44.84 \%)$ degree or vocational education accreditation $27.69 \%$. Those with ten or more years' experience $(43.96 \%)$ were significantly higher than the next group of managers with $6-10$ years of work experience (27.03\%).

\subsection{Goodness-of-fit (GoF) analysis}

A GoF assessment was made for the model's fit during the CFA. From that, all indices were validated (Table 1). 
Table 1. GoF criteria, values, and supporting theory.

\begin{tabular}{|l|c|c|c|}
\hline \multicolumn{1}{|c|}{ Statistic } & Criteria & Values & Theory \\
\hline$\chi 2$ & $p \geq 0.05$ & 0.68 & {$[35]$} \\
\hline$\chi 2$ / df degrees of freedom & $\leq 2.00$ & 0.92 & {$[36]$} \\
\hline RMSEA & $\leq 0.05$ & 0.00 & {$[37]$} \\
\hline Goodness-of-fit index (GFI) & $\geq 0.90$ & 0.98 & {$[35]$} \\
\hline Adjusted goodness-of-fit index (AGFI) & $\geq 0.90$ & 0.96 & {$[38]$} \\
\hline Root mean square residual (RMR) & $\leq 0.05$ & 0.02 & {$[39]$} \\
\hline Standardized root mean square residual (SRMR) & $\leq 0.05$ & 0.03 & {$[37]$} \\
\hline Normed fit index (NFI) & $\geq 0.90$ & 0.99 & {$[40]$} \\
\hline Comparative fit index [CFI) & $\geq 0.90$ & 1.00 & {$[41]$} \\
\hline$\alpha$ & $\geq 0.70$ & $0.73-0.86$ & {$[32]$} \\
\hline
\end{tabular}

\subsection{CFA analysis of external and internal variables}

The results of the analysis on the external latent variables STY and TIN are presented in Table 2, while Table 3 details the internal latent variables TQM, QLY, QLY, and KNG results.

Table 2. CFA analysis for the external variables STY and TIN.

\begin{tabular}{|c|c|c|c|c|c|c|}
\hline Construct & $\alpha$ & AVE & t-value & Manifest variables & loading & $\mathbf{R}^{2}$ \\
\hline \multirow{3}{*}{ STY } & \multirow{3}{*}{0.79} & \multirow{3}{*}{0.42} & \multirow{3}{*}{0.68} & Cost leadership (x1) & 0.59 & .34 \\
\hline & & & & Service difference $(\mathrm{x} 2)$ & 0.55 & .30 \\
\hline & & & & Target group focus $(\mathrm{x} 3)$ & 0.77 & .59 \\
\hline \multirow{3}{*}{ TIN } & \multirow{3}{*}{0.86} & \multirow{3}{*}{0.58} & \multirow{3}{*}{0.87} & Supply chain process $(\mathrm{x} 4)$ & 0.75 & .57 \\
\hline & & & & Product development (x5) & 0.85 & .72 \\
\hline & & & & Product and process design (x6) & 0.79 & .62 \\
\hline
\end{tabular}

$\alpha=$ significance level.

Table 3. CFA analysis for the internal variables TQM, QLY, QLY, and KNG.

\begin{tabular}{|c|c|c|c|c|c|c|}
\hline $\begin{array}{c}\text { Latent } \\
\text { variables }\end{array}$ & $\alpha$ & AVE & t-value & Manifest variables & loading & $\mathbf{R}^{2}$ \\
\hline \multirow{5}{*}{ TQM } & 0.73 & 0.42 & 0.78 & Leadership (y1) & 0.68 & .46 \\
\hline & & & & Quality management source (y3) & 0.58 & .33 \\
\hline & & & & Consumer focus (y4) & 0.62 & .39 \\
\hline & & & & People management (y5) & 0.66 & .43 \\
\hline & & & & Compensation management (y7) & 0.70 & .49 \\
\hline \multirow{3}{*}{ QLY } & 0.82 & 0.49 & 0.74 & Product conformity (y8) & 0.70 & .49 \\
\hline & & & & Reliability(y10) & 0.62 & .38 \\
\hline & & & & Product features (y11) & 0.77 & .60 \\
\hline \multirow{3}{*}{ KNG } & 0.79 & 0.47 & 0.72 & Acquisition of knowledge (y13) & 0.68 & .45 \\
\hline & & & & Spreading awareness (y14) & 0.78 & .61 \\
\hline & & & & Application of knowledge (y15) & 0.58 & .34 \\
\hline
\end{tabular}

$\alpha=$ significance level. 


\subsection{Questionnaire latent variable descriptive analysis}

Table 4 shows the descriptive analysis of five latent variables, with STY ranked most important by the survey respondents $(\bar{x}=4.11)$, with TQM second $(\bar{x}=4.05)$, followed closely by KNG $(\bar{x}=4.00)$.

Table 4. Descriptive analysis of the latent variables.

\begin{tabular}{|l|c|c|c|c|}
\hline \multicolumn{1}{|c|}{ Latent Variable } & $\overline{\boldsymbol{x}}$ & S.D. & Skewness & Kurtosis \\
\hline STY & 4.11 & .65 & -.42 & -.07 \\
\hline TIN & 3.73 & .70 & -.05 & -.35 \\
\hline TQM & 4.05 & .62 & -.36 & .06 \\
\hline QLY & 3.94 & .67 & -.20 & -.50 \\
\hline KNG & 4.00 & .72 & -.25 & -.76 \\
\hline
\end{tabular}

S.D. $=$ standard deviation, $\bar{x}=$ mean.

\subsection{SEM reliability results}

Table 5 shows the results from the internal consistency testing [42]. Figure 2 then presents the final SEM results of the hypotheses testing.

Table 5. Latent variables correlation coefficients ( $r$ ) (under the bold), CR, and AVE values.

\begin{tabular}{|c|c|c|c|c|c|}
\hline Latent variables & STY & TIN & TQM & QLY & KNG \\
\hline STY & 1.00 & & & & \\
\hline TIN & $.40^{* * *}$ & 1.00 & & & \\
\hline TQM & $.74 * *$ & $.40 * *$ & 1.00 & & \\
\hline QLY & $.66^{* *}$ & $.45 * *$ & $.74 * *$ & 1.00 & \\
\hline KNG & $.60 * *$ & $.46 * *$ & $.68 * *$ & $.67 * *$ & 1.00 \\
\hline$\rho_{\mathrm{V}}(\mathrm{AVE})$ & 0.75 & 0.58 & 0.44 & 0.60 & 0.48 \\
\hline$\rho_{\mathrm{C}}($ Composite Reliability $)$ & 0.91 & 0.87 & 0.79 & 0.82 & 0.73 \\
\hline$\sqrt{\mathrm{AVE}}$ & 0.86 & 0.76 & 0.66 & 0.77 & 0.69 \\
\hline
\end{tabular}

$* *$ Sig. $\leq .01$.

\subsection{Effect decomposition}

It was determined from the analysis that STY $(\mathrm{TE}=0.76)$ had the strongest influence on TQM, followed closely by KNG $(\mathrm{TE}=0.75)$ (Table 6). Minor influences but still positive were QLY (TE $=0.26)$ and TIN (TE $=0.25)$. Finally, all the model's factors had a positive influence on TQM, which are combined to explain the variance of the factors affecting TQM (R (2by $78 \%$. 
Table 6. Mediation effects influencing TQM.

\begin{tabular}{|c|c|c|c|c|c|c|}
\hline \multirow{2}{*}{ Dependent variables } & \multirow{2}{*}{$\mathbf{R}^{2}$} & \multirow{2}{*}{ Effect } & \multicolumn{4}{|c|}{ Independent variables } \\
\hline & & & $S T Y$ & TIN & $Q L Y$ & $K N G$ \\
\hline \multirow{3}{*}{ TQM } & \multirow{3}{*}{.78} & $\mathrm{DE}$ & $0.28 * *$ & - & $0.26^{*}$ & $0.56^{* *}$ \\
\hline & & IE & $0.48^{* *}$ & $0.25 * *$ & - & $0.19 *$ \\
\hline & & TE & $0.76^{* *}$ & $0.25 * *$ & $0.26^{*}$ & $0.75 * *$ \\
\hline \multirow{3}{*}{ QLY } & \multirow{3}{*}{.51} & $\mathrm{DE}$ & 0.06 & $0.12 *$ & & $0.75^{* * *}$ \\
\hline & & IE & $0.46^{* *}$ & $0.22 * *$ & & - \\
\hline & & TE & $0.52 * *$ & $0.34 * *$ & & $0.75^{* * *}$ \\
\hline \multirow{3}{*}{ KNG } & \multirow{3}{*}{.60} & $\mathrm{DE}$ & $0.61^{* *}$ & $030 * *$ & & \\
\hline & & $\mathrm{IE}$ & - & - & & \\
\hline & & TE & $0.61 * *$ & 030 ** & & \\
\hline
\end{tabular}

$*$ Sig. $\leq .05, * *$ Sig. $\leq .01, \mathrm{R}^{2}=$ coefficient of determination, KAC = Knowledge Absorption Capability., direct effect (DE), indirect effect (IE), and the total effect (TE).

\subsection{SEM results}

Table 7 and Figure 2 show the results from the analysis on Thai auto parts TQM. Key elements included $\chi 2=16.93$ (not statistically significant), df $=13, \mathrm{p}$-value $=$ 0.20239 , and RMSEA $=30.27$.

Table 7. SEM hypotheses testing results.

\begin{tabular}{|l|c|c|l|}
\hline \multicolumn{1}{|c|}{ Hypotheses } & r & t-value & \multicolumn{1}{c|}{ Results } \\
\hline H1: STY directly and positively affects KNG & 0.61 & $9.48^{* *}$ & Consistent \\
\hline H2: STY directly and positively affects QLY & 0.06 & 0.68 & Inconsistent \\
\hline H3: STY directly and positively affects TQM & 0.28 & $3.64 * *$ & Consistent \\
\hline H4: TIN directly and positively affects KNG & 0.30 & $5.95 * *$ & Consistent \\
\hline H5: TIN directly and positively affects QLY & 0.12 & $2.27 *$ & Consistent \\
\hline H6: KNG directly and positively affects QLY & 0.75 & $6.57 * *$ & Consistent \\
\hline H7: KNG directly and positively affects TQM & 0.56 & $3.45^{* *}$ & Consistent \\
\hline H8: QLY directly and positively affects TQM & 0.26 & $2.03 *$ & Consistent \\
\hline
\end{tabular}

$*$ Sig. $\leq 0.05, * *$ Sig. $\leq 0.0$, correlation coefficient $=r$

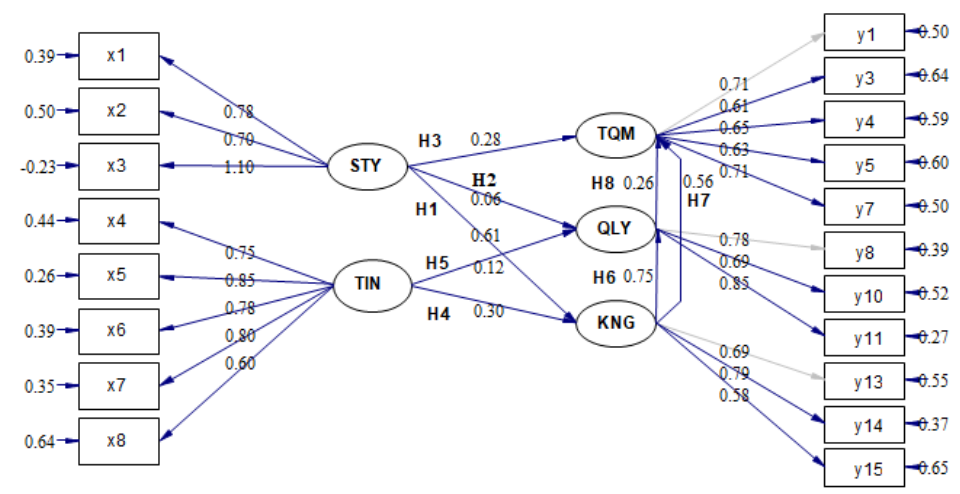

Fig. 2. TQM final model 


\section{Discussion}

The final results from the SEM analysis of the variables influencing a Thai auto parts enterprise TQM determined that when ranked in importance, STY $(\mathrm{TE}=0.76)$ and KNG $(\mathrm{TE}=0.75)$ were nearly evenly matched and had a strong influence. On the other, QLY $(\mathrm{TE}=0.26)$ and TIN $(\mathrm{TE}=0.25)$ exhibited weak influences. Therefore, the following detail and supporting discussion are provided.

\subsection{Strategic planning}

The study authors developed three hypotheses in their conceptualization. The first relationship (H1) between STY and KNG was found to be both direct and positive with $r=0.61$, t-test value $=9.48$, and the significance $p \leq 0.01$, which indicates a moderate to a strong positive relationship.

The second relationship (H2); however, between STY and QLY was found to be extremely weak with $r=0.06$ and the $t$-value $=0.68$. Therefore, the authors rejected the hypothesis.

The third relationship (H3) between STY and TQM was also found to be both direct and positive with $r=0.28$, t-test value $=3.64$, and the significance $p \leq 0.01$, which indicates a weak to a moderate relationship.

However, the importance of strategy in determining competitive outcomes in either domestic or international markets was confirmed [43], but global strategy adoption can be risky, which requires managers to think in new ways.

\subsection{Technology and innovation (TIN)}

Concerning TIN, the authors developed two further hypotheses in their conceptualization. The first relationship (H4) between TIN and KNG was found to be both direct and positive with $r=0.30$, t-test value $=2.27$, and the significance $p \leq 0.01$, which indicates a moderately positive relationship.

Hypothesis H5 explored the relationship between TIN and QLY, which was also found to be both direct and positive with $\mathrm{r}=0.12$, t-test value $=5.95$, and the significance $\mathrm{p} \leq 0.05$, which indicates a weak, but a positive relationship.

In automotive industry literature, authors have suggested that today's vehicles are nothing more than computers with wheels, as a new Ford F-150 pickup contains 150 million lines of code [44]. Also, Accenture has reported that today's vehicles collect approximately 25 gigabytes of data per hour from various onboard sensors [45], which allows for real-time insights to be drawn about such things as performance, speed, and component condition. This creates an essential need for ongoing code management and service, where highly connected IoT 'pushing' software updates to the owner's vehicles while having the ability to track defective components [7].

As the Thai auto parts industry transitions from combustion engines running on fossil fuels to autonomous EVs, the requirement for TIN will not only be necessary to maintain competitiveness but for a firm's very survival [9]. The knock-on effect of 
these looming disruptive technologies is just now being explored, and most probably is not understood by many Thai firms and their managers. The Thai government, therefore, needs to face this reality and find solutions for the propagation of technological change.

\subsection{Knowledge management (KNG)}

The next set of hypotheses that were examined was between KNG to QLY (H6) and between KNG to TQM (H7). The first relationship (H6) was found to be both direct and positive with $r=0.0 .75$, $t$-test value $=6.57$, and the significance $p \leq 0.01$. This indicates a strong positive relationship. Additionally, $\mathrm{H} 7$ was found to be both direct and positive with $r=0.0 .56$, $t$-test value $=3.45$, and the significance $p \leq 0.01$, which also indicates a strong positive relationship.

\subsection{Product quality (QLY)}

The final hypothesis tested was H8, which was the relationship between QLY to TQM, with $r=0.0 .26$, t-test value $=2.03$, and the significance $\mathrm{p} \leq 0.05$, which indicates a weak but positive relationship.

A consensus has developed that by the use of an integrated approach to product quality, TQM can be achieved. In Thailand, however, where the majority of auto parts manufacturers are SMEs, TQM is challenging to implement and often not understood by the managers [46]. The authors, therefore, believe that this is the reason for the weak relationship in $\mathrm{H} 8$.

\subsection{Total quality management (TQM)}

In India, it was argued that TQM and information systems could be quite useful to the final consumer[47], with organizational culture also crucial to the failure or success of a TQM implementation [48], [49]. This is consistent with an Australian study by [50], which also reported that when an organization cannot integrate TQM and cultural change, TQM failure is most likely.

In Malaysia, effective TQM in SMEs was determined to come from the top-down as well as getting employees involved, the method and means of their rewards, and the development of skills [51].

\section{Conclusion}

The study investigated how total quality management was affected by knowledge management, product quality, strategic planning, and technology and innovation within the Thai auto parts industry. The effectiveness and validation of the study's SEM were also validated.

From the analysis, it was determined that disruptive change would force consolidation and company failures. New digital technologies and processes related to big data 
and artificial intelligence will radically alter how firms will compete and remain competitive. Competition is proliferating rapidly in the ASEAN trade block with nations such as Indonesia and Vietnam are seen as direct threats to Thailand's leadership role within the automotive and auto parts export sector.

One bright light within the domestic Thai auto parts market is the size of the automobile and motorcycle fleets, as the replacement equipment manufacturing (REM) products will see ongoing growth. As recently as July 2019, Thailand Department of Land Transport (DLT) was reporting that there were 40.19 million registered vehicles in Thailand, of which 21.05 million were motorcycles [52].

However, Thai auto parts industry managers and executives need to understand industry structures are continually evolving, and due to technology, accelerating. Competitors will always try to push trends away from the strengths of the industry leaders, as in the case with Indonesia, which has stated they want to take Thailand's ASEAN automotive hub leadership away. Critical elements involve a quick appraisal of how new technologies can be brought into current or future TQM processes. This will require management's adaptability, flexibility, strategic planning, and access to innovative individuals.

\section{$7 \quad$ References}

[1] P. Maikaew, "Automotive industry at a turning point," Bangkok Post, January 7, 2019, [Online], Available: https://tinyurl.com/ya3njco6. [Accessed Oct. 18, 2019].

[2] A. Phoonphongphiphat, "Thai automakers are desperate to keep high tariff on imported cars," Nikkei Asian Review, February 20, 2018, [online], Available: https://tinyurl.com/yxp6napg. [Accessed Oct. 18, 2019].

[3] W. Yongpisanphob, "Thailand industry outlook 2017-2019: Auto parts industry. Krungsri Research, 2017, [online], Available: https://tinyurl.com/yxz8yf3c. [Accessed Oct. 18, 2019].

[4] S. Dansomboon, T. Phimonsathienand, and W. Fongsuwan, "Cross-cultural logistics and supply chain management towards organizational effectiveness within the Asean/Thai automotive industries: A SEM analysis," Management and Production Engineering Review, vol. 7, no. 3, pp. 23 - 38, 2016. https://doi.org/10.1515/mper-2016-0023

[5] P. Maikaew, "The man behind Thai auto policy," Bangkok Post, April 27, 2019, https://tinyurl.com/y27ndrxy. [Accessed Oct. 18, 2019].

[6] J. Rosas, V. Brito, L. B. Palma, and J. Barata, "Approach to Adapt a Legacy Manufacturing System Into the IoT Paradigm," International Journal of Interactive Mobile Technologies (iJIM), vol. 11, no. 5, pp. 91 - 104, 2017. https://doi.org/10.3991/ijim.v11i5.7073

[7] U. Muench, "New automotive DNA: How IoT is transforming the automotive industry," Digitalist Magazine, April 20, 2018, [online], Available: https://tinyurl.com/y6c4zh5r. [Accessed Oct. 18, 2019].

[8] J. Majava, and V. Isoheranen, "Business model evolution of customer care services," Journal of Industrial Engineering and Management, vol. 12, no. 1, pp. 1-12, 2019. https:// doi.org/10.3926/jiem.2725

[9] H. Schoenfeld, "The Paradigm Shift In The Auto Industry Caused By E-Mobility, E-3 Magazine International, March 21, 2018, https://tinyurl.com/y37djz7m. [Accessed Oct. 18, 2019]. 
[10] J. Schreurs, "Total Quality Management (TQM) framework for e-learning based on EFQM and Kirkpatrick models," International Journal of Emerging Technologies in Learning (iJET), vol. 1, no. 3, 1 - 6, 2006, [online], Available: https://tinyurl.com/yycrms56. [Accessed Oct. 18, 2019].

[11] H. J. Harrington, "Performance improvement: was W. Edwards Deming wrong?" The TQM Magazine, vol. 10, no. 4, pp. 230 - 237, 1998. https://doi.org/10.110 8/09544789810222595

[12] K. Ishikawa, What Is Total Quality Control? The Japanese Way. Englewood Cliffs, NJ: Prentice-Hall, 1985.

[13] A. V. Feigenbaum, Quality control: Principles, practice and administration: An industrial management tool for improving product quality and design and for reducing operating costs and losses, New York, NY: McGraw-Hill, 1951.

[14] A. V. Feigenbaum, Total quality control, New York, NY: McGraw-Hill, 1983.

[15] J. Álvarez-García, A. Durán-Sánchez, and M. C. del Río-Rama, "Systematic bibliometric analysis on Kaizen in scientific journals," The TQM Journal, vol. 30, no. 4, pp. 356-370, 2018. https://doi.org/10.1108/TQM-12-2017-0171

[16] C. H. Chung, "The Kaizen Wheel - an integrated philosophical foundation for total continuous improvement," The TQM Journal, vol. 30, no. 4, pp. 409 - 424, 2018. https://doi. org/10.1108/tqm-03-2018-0029

[17] T. Kozaki, A. Ooura, and K. Amasaka, "Establishment of TQM promotion diagnosis model "TQM-PDM" for strategic quality management," in the 40th International Conference on Computers \& Industrial Engineering, 2010. https://doi.org/10.1109/iccie.2010.5668337

[18] S. Leonard, and R. McAdam, "The relationship between total quality management (TQM) and corporate strategy: The strategic impact of TQM," Strategic Change, vol. 10, no. 8, pp. 439 - 448, 2002. https://doi.org/10.1002/jsc.565

[19] J. J. Oschman, "The Role of Strategic Planning in Implementing a Total Quality Management Framework: An Empirical View," Quality Management Journal, 24(2), 41 - 53. https://doi.org/10.1080/10686967.2017.11918508

[20] McKinsey Global Institute, "Twenty-five years of digitization: Ten insights into how to play it right," 2019. Retrieved from https://tinyurl.com/yydyhtrh

[21] F. Barachini and S. Rankl, "The relevance of knowledge and innovation management for the European automotive supply industry: A case study," in Knowledge Management: Competencies and Professionalism, S. Hawamdeh, K. Stauss, and F. Barachini, Eds. World Scientific. 2008, pp. 159-169. https://doi.org/10.1142/9789812837578_0014

[22] R. Y-Y. Hung, B. Y-H. Lien, S-C. Fang, and G. N. McLean, "Knowledge as a facilitator for enhancing innovation performance through total quality management," Total Quality Management \& Business Excellence, vol. 21, no. 4, pp. 425 - 438, 2010. https://doi.org/10. $\underline{1080 / 14783361003606795}$

[23] R. A. Rahim, N. H. N. Mahmood, and M. Masrom, "The role of knowledge management in facilitating innovation for sustainable SMEs performance," In Proc. of the 2015 International Conference on Technology, Informatics, Management, Engineering and Environment, TIME-E 2015, 2016. https://doi.org/10.1109/TIME-E.2015.7389749

[24] Y-L. Lai, M-S.Hsu, F-J. Lin, Y-M. Chen, and Y-H. Lin, "Knowledge management emerges as the mediator of industry clusters in terms of corporate innovation performance. The effects of industry cluster knowledge management on innovation performance," Journal of Business Research, vol. 67, no. 5, pp. 734-739, 2014. https://doi.org/10.1016/j. jbusres.2013.11.036 
[25] B. Borgström, and Hertz, S. "Supply chain strategies: Changes in customer order-based production," Journal of Business Logistics, vol. 32, no. 4, pp. 361-373, 2011. https://doi.org/10.1111/j.0000-0000.2011.01031.x

[26] D. A. Garvin, Managing quality: The strategic and competitive edge, New York, NY: Free Press, 1988.

[27] I. Goicoechea and M. Fenollera, "Quality management in the automotive industry, Chapter 51," in DAAAM International Scientific Book, B. Katalinic, Ed., Vienna, Austria: DAAAM International, 2012, pp. 619-632. https://doi.org/10.2507/daaam.scibook.2012.51

[28] S. Friedman, Roles, responsibilities, and resources: best practices in managing people. Paper presented at PMI ${ }^{\circledR}$ Global Congress 2008-North America, Denver, CO. Newtown Square, PA: Project Management Institute, 2008. Retrieved from https://tinyurl. com/yxczquor

[29] H. Beheshti, and J. Lollar, "An empirical study of US SMEs using TQM," Total Quality Management \& Business Excellence, vol. 14, no. 8, pp. 839-847, 2003. https://doi.org/10.1080/1478336032000090798

[30] G. Velmurugan, R. Shubasini, N. SaravanaBhavan, and V. Selvam, "A Study on Service Quality of a Health Care Organization," International Journal of Online and Biomedical Engineering (iJOE), vol. 15, no. 10, 91 - 106, 2019. https://doi.org/10.39 91/ijoe.v15i10.10906

[31] R. Ramphal, and A. Nicolaides, "Service and quality and quality service: Satisfying customers in the hospitality industry," African Journal of Hospitality, Tourism and Leisure, vol. 3, no. 2, pp. 1 - 19, 2014. Retrieved from https://tinyurl.com/yxm3vosp

[32] D. George, and P. Mallery, SPSS for Windows step by step: A simple guide and reference. 11.0 update, Boston: Allyn \& Bacon, 2003. https://doi.org/10.4324/9781351033909

[33] J. C. Loehlin, Latent variable models, Hillsdale, NJ: Lawrence Erlbaum Publishers, 1992.

[34] D. J. Bartholomew, F. Steele, I. Moustaki, and J. I. Galbraith, Analysis of multivariate social science data, Boca Raton, Fl: CRC Press, 2008.

[35] K. G.Jöreskog, U. H. Olsson, and Y. W. Fan, Multivariate analysis with LISREL. Berlin, Germany, 2016.

[36] B. M. Byrne, R. J. Shavelson, and B. Muthén, "Testing for the equivalence of factor covariance and mean structures: The issue of partial measurement invariance," Psychological Bulletin, vol. 105, no. 3, pp. 456-466, 1989. https://doi.org/10.1037//0033-2909.105.3.456

[37] P-W. Lei, and Q. Wu, "Introduction to structural equation modeling: Issues and practical considerations," Educational Measurement: Issues and Practice, vol. 26, no. 3, pp. 33 43. 2007. https://doi.org/10.1111/j.1745-3992.2007.00099.x

[38] D. Hooper, J. Coughlan, and M. Mullen, "Structural equation modelling: Guidelines for determining model fit," Electronic Journal of Business Research Methods, vol. 6, no. 1, pp. 53-60, 2008. Retrieved from http://tinyurl.com/zyd6od2

[39] L. T. Hu, and P. M. Bentler, "Cutoff criteria for fit indexes in covariance structure analysis: Conventional criteria versus new alternatives," Structural Equation Modeling, vol. 6, no. 1, pp. 1 - 55, 1999. https://doi.org/10.1080/10705519909540118

[40] P. M. Bentler, and D. G. Bonett, "Significance tests and goodness of fit in the analysis of covariance structures. Psychological Bulletin, vol. 88, no. 3, pp. 588-606. 1980. https://doi. org/10.1037/0033-2909.88.3.588

[41] R. E. Schumacker, and R. G. Lomax, A Beginner's Guide to Structural Equation Modeling. New York, NY: Routledge, 2010.

[42] B. Ratner, "The $r$ : Its values range between $+1 /-1$, or do they?" Journal of Targeting, Measurement, and Analysis for Marketing, vol. 17, no. 2, pp. 139 - 142, 2009. https://doi. org/10.1057/jt.2009.5 
[43] T. Hout, M. W. Porter, and E. Rudden, "How Global Companies Win Out," Harvard Business Review, September, 1982. Retrieved from https://tinyurl.com/y4a8ly9k

[44] R. Saracco, "Guess what requires 150 million lines of code....," EIT Digital, January 16, 2016, [online], Available: https://tinyurl.com/hhdwwhn [Accessed Oct. 18, 2019].

[45] M. Tamietti, and G. Seiberth, "The 2018 top ten automotive predictions. Accenture, 2018. Retrieved from https://tinyurl.com/yytaew3w. [Accessed Oct. 18, 2019].

[46] D. Niven, "When Times Get Tough, What Happens to TQM?" Harvard Business Review, May-June, 1993. Retrieved from https://tinyurl.com/y5yzj5x9

[47] J. Siddiqui, and Z. Rahman, "TQM principles' application on information systems for empirical goals: A study of Indian organizations. The TQM Magazine, vol. 19, no. 1, pp. 7687. 2007. https://doi.org/10.1108/09544780710720853

[48] A. A. Eniola, G. K. Olorunleke, O.O. Akintimehin, J. D. Ojeka, and B. Oyetunji, "The impact of organizational culture on total quality management in SMEs in Nigeria," Heliyon, vol. 5, no. 8, pp. 2 - 10, 2019. https://doi.org/10.1016/j.heliyon.2019.e02293

[49] D. I. Prajogo, and C. M. McDermott, "The relationship between total quality management practices and organizational culture," International Journal of Operations \& Production Management, vol. 25, no. 11, pp. 1101-1122. 2005. https://doi.org/10.1 $\underline{108 / 01443570510626916}$

[50] K. S. Cameron, and R. E. Quinn, "Diagnosing and changing organizational culture: Based on the competing values framework," San Francisco, CA: Jossey-Bass, 2006.

[51] M. N. A. Rahman, and J. D. T. Tannock, "TQM Best Practices: Experiences of Malaysian SMEs," Total Quality Management \& Business Excellence, vol. 16, no. 4, pp. 491 - 503, 2005. https://doi.org/10.1080/14783360500078540

[52] On a plate: DLT hands out registration stats, The Nation, July 15, 2019, [online], Available: https://tinyurl.com/y4ugawxt. [Accessed Oct. 18, 2019].

\section{Authors}

Att Petcharit is a doctoral student with the Faculty of Administration and Management at the King Mongkut's Institute of Technology Ladkrabang (KMITL), Bangkok, Thailand.

Puris Sornsaruht is an assistant professor with the Faculty of Administration and Management at the King Mongkut's Institute of Technology Ladkrabang (KMITL), Bangkok, Thailand. He graduated with a Bachelor of Engineering degree from Chiang Mai University, Thailand. Afterwards, he was awarded a Master's Degree in Business from Ramkhamhaeng University and a Ph.D. in Industrial Business Administration from KMITL. He has specialized in industrial business administration, tourism, and marketing.

Paitoon Pimdee is an Associate Professor with the Faculty of Industrial Education and Technology and Vice President of Procurement at the King Mongkut's Institute of Technology Ladkrabang (KMITL), Bangkok, Thailand. He also serves has the faculty head of the Ph.D. program, and the head of the Department of Industrial Education and Technology. He graduated with a B.A. in Economics and a M.Sc. in science education. He also holds a Ph.D. in environmental education, and specializes in environmental behaviors, conservation behaviors, educational research and statistics.

Article submitted 2019-10-19. Resubmitted 2019-11-27. Final acceptance 2019-12-03. Final version published as submitted by the authors. 